\title{
The clinicopathological features of colorectal mucinous adenocarcinoma and a therapeutic strategy for the disease
}

\author{
Masakatsu Numata ${ }^{1 *}$, Manabu Shiozawa ${ }^{1}$, Takuo Watanabe$^{1}$, Hiroshi Tamagawa ${ }^{1}$, Naoto Yamamoto ${ }^{1}$, \\ Soichiro Morinaga' ${ }^{1}$, Kazuteru Watanabe ${ }^{2}$, Teni Godai ${ }^{2}$, Takashi Oshima², Shoichi Fujii' ${ }^{2}$, Chikara Kunisaki ${ }^{2}$, \\ Yasushi Rino ${ }^{3}$, Munetaka Masuda ${ }^{3}$ and Makoto Akaike ${ }^{1}$
}

\begin{abstract}
Background: The guidelines established by the National Comprehensive Cancer Network do not describe mucinous histology as a clinical factor that should influence the therapeutic algorithm. However, previous studies show conflicting results regarding the prognosis of colorectal mucinous adenocarcinoma. In this study, we described the clinicopathological features of mucinous adenocarcinoma in Japan, to identify optimal therapeutic strategies.

Methods: 144 patients with mucinous and 2673 with non-mucinous adenocarcinomas who underwent primary resection in two major centers in Yokohama, Japan were retrospectively evaluated for clinicopathological features and treatment factors. A multivariate analysis for overall survival followed by the comparison of overall survival using Cox proportional hazard model were performed.

Results: Patients with mucinous adenocarcinoma had larger primary lesions, higher preoperative CEA levels, a deeper depth of invasion, higher rates of nodal and distant metastasis, and more metastatic sites. A multivariate analysis for overall survival revealed a mucinous histology to be an independent prognostic factor. In the subgroup analysis stratified by stage, Patients diagnosed as Stagell and IV disease had a worse survival in mucinous adenocarcinoma than non-mucinous, while survival did not differ significantly in patients diagnosed as Stage0-\| disease. In Stagelll, local recurrence in rectal cases and peritoneal dissemination were more frequently observed in patients with a mucinous histology.

Conclusions: Our study indentified that mucinous adenocarcinoma was associated with a worse survival compared with non-mucinous in patients with Stagelll and IV disease. In rectal Stagelll disease with mucinous histology, additional therapy to control local recurrence followed by surgical resection may be a strategical alternative. Further molecular investigations considering genetic features of mucinous histology will lead to drug development and better management of peritoneal metastasis
\end{abstract}

Keywords: Mucinous adenocarcinoma, Colorectal cancer, Clinicopathological feature

\footnotetext{
* Correspondence: masakatsunumata@hotmail.co.jp

${ }^{1}$ Department of Gastroenterological Surgery, Kanagawa Cancer Center, 1-1-2

Nakao, Asahi-ku, Yokohama, Kanagawa 241-0815, Japan

Full list of author information is available at the end of the article
} 


\section{Background}

Colorectal cancer is the third most common cancer and the fourth most frequent cause of cancer death worldwide [1]. Mucinous adenocarcinoma (MA) is diagnosed when more than $50 \%$ of the tumor comprises a mucinous pattern upon histological examination [2]. MA makes up 6 to $20 \%$ of all colorectal cancers [3-8], and differs from non-mucinous adenocarcinoma (NMA) with regard to its clinicopathological characteristics, distinct genetic profiles, and pathogenic pathways [9-12].

The prognostic significance of MA is controversial. In previous studies, mucinous histology was reported not to be an independent prognostic factor for survival $[13,14]$. The guidelines established by the National Comprehensive Cancer Network (NCCN) do not describe mucinous histology as a clinical factor that should influence the therapeutic algorithm $[15,16]$. However, in some studies, it is reported that MA is associated with worse clinicopathological characteristics [17-19] and a poorer prognosis than NMA [5,17,20-23].

The lack of a consensus may be the result of the low ratio of MA to all colorectal cancers and the limited detection power to clarify the differences between MA and NMA.

We conducted a retrospective analysis of patients with colorectal cancer at two major centers to identify the clinicopathological features of MA, and also investigated the recurrence to establish an optimal therapeutic strategy for MA.

\section{Methods \\ Patients}

The data from 2,817 patients with colorectal cancer in two major centers, Kanagawa Cancer Center and Yokohama City University Medical Center, between 2001 and 2010 were investigated. Written informed consent was obtained from the patient for publication of this report and any accompanying images. All patients initially underwent resection of a primary lesion followed by adjuvant chemotherapy when diagnosed as stage III disease. In tumor, node metastases (TNM) stage T3 to T4, lower-rectal cases, total mesorectal excision (TME) and lateral node dissection were routinely performed at initial resection. No patients were treated with neo- or adjuvant radiation therapy.

The analyzed patients were diagnosed with MA, defined as tumors with more than $50 \%$ of the tumor volume comprising mucin, or with NMA, defined as tumors without any mucinous features, or with a less than 50\% mucinous component [2]. Patients diagnosed with signet ring cell carcinoma, undifferentiated carcinoma, and other histological types were excluded from the analysis.
The covariates included in the study were gender, age, location of the tumor, size of the primary tumor, preoperative serum carcinoembryonic antigen (CEA) level, depth of invasion, lymph node metastasis, distant metastasis, operating facility, and histological type. The pathological tumor status was coded using the TNM classification system [24]. The use of adjuvant chemotherapy for patients with curative resection, as well as additional therapy (chemotherapy and/or surgery) for recurrent and non-curative cases were also recorded.

In the analysis of the survival rates, all cases were divided into 3 groups, that is, patients without any metastases (stage 0 to II [24]), patients with regional lymph node metastasis but without distant metastasis (stage III), and patients with distant metastasis (stage IV).

\section{Statistical analysis}

The two groups of patients (MA and NMA) were compared using $2 \times 2$ tables for binary factors using the $x^{2}-$ test, or Fisher's exact test where appropriate. Overall survival was calculated from the date of surgery for the primary lesion until death from any cause, or was censored at the last follow-up visit. Survival data were analyzed using the Kaplan-Meier method. A comparison of survival curves was carried out using the log-rank test. The prognostic significance was analyzed by multivariate Cox proportional hazard models. $P$-values $<0.05$ were considered statistically significant, and all $P$-values correspond to two-sided significance tests.

\section{Results}

Of the 2,817 colorectal cancer patients, MA accounted for $5.1 \%$ (144) of the colorectal cancer cases. The distribution of the patients' characteristics is shown in Table 1. The distribution for gender, age, and location of MA was similar to that of NMA. The patients with MA had significantly larger primary lesions, higher preoperative serum CEA levels, deeper invasion, higher nodal and distant metastasis rates, and a larger number of metastatic sites compared to the patients with NMA.

Table 2 shows the distribution of treatment factors, including the curability of the first surgery, rate of adjuvant chemotherapy, chemotherapy for advanced or recurrent cases, and additional surgery for liver and lung metastasis. For these factors, there were no significant differences between the MA and NMA groups. Unlike western countries, neo- or adjuvant radiation therapy for patients with stage II and III disease is not commonly performed in Japan.

To clarify the prognostic factors for colorectal cancer, univariate and multivariate analysis were carried out. Mucinous histology was noted to be one of the independent prognostic factors for overall survival in univariate and multivariate analysis (Tables 3 and 4). The 5-year relative 
Table 1 Comparison of clinicopathological characteristics in non-mucinous and mucinous adenocarcinoma

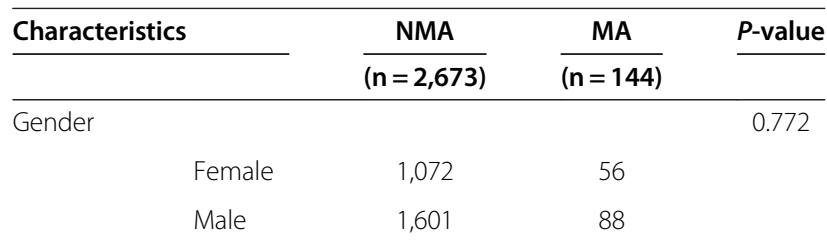

Age, years

$\begin{array}{lll}<65 & 1,183 & 57 \\ \geqq 65 & 1,490 & 87\end{array}$

Location

$\begin{array}{lll}\text { Colon } & 1,516 & 92 \\ \text { Rectum } & 1,157 & 57\end{array}$

Size, $\mathrm{cm}$

$\begin{array}{lll}<5 & 1,715 & 59 \\ \geq 5 & 958 & 85\end{array}$

Preoperative serum CEA, ng/ml

$\begin{array}{ccc}<5.0 & 1,858 & 80 \\ \geqq 5.0 & 815 & 64\end{array}$

Depth of

invasion $^{\mathrm{a}}$

$\begin{array}{ccc}\mathrm{T} 1, \mathrm{~T} 2 & 979 & 13 \\ \mathrm{~T} 3, \mathrm{~T} 4 & 1,694 & 131\end{array}$

Lymph node metastasis $^{\mathrm{a}}$

$\begin{array}{lll}\text { No } & 1,602 & 68 \\ \text { N1, N2 } & 1,071 & 76\end{array}$

Distant

metastasis $^{\mathrm{a}}$

$\begin{array}{lrr}\text { M0 } & 2,319 & 114 \\ \text { M1 } & 354 & 30\end{array}$

Number of

metastatic sites

$\begin{array}{lcc}0 & 2,319 & 114 \\ 1 & 269 & 25 \\ \geqq 2 & 86 & 5\end{array}$

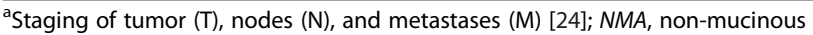
adenocarcinoma; $M A$, mucinous adenocarcinoma.

survival rate of the MA patients was $52.2 \%$, which was significantly worse than that of the NMA patients (73.8\%), with a median follow-up of 52 months (range 1 to 128 months) (Figure 1).

We next divided all cases into 3 groups (stage 0 to II, stage III, and stage IV) to compare the overall survival in each group. There were no significant differences in 5-year survival in stage 0 to II based on the histological status (MA: $88.5 \%$ vs. NMA: 91.0\%, $P=0.099$ ) (Figure 2).
Table 2 Comparison of treatment factors in non-mucinous and mucinous adenocarcinoma

\begin{tabular}{|c|c|c|c|}
\hline Treatment factors & NMA & MA & $P$-value \\
\hline Curability of first surgery & $n=2,673$ & $n=144$ & 0.063 \\
\hline Complete & 2,411 & 123 & \\
\hline Incomplete & 262 & 21 & \\
\hline $\begin{array}{l}\text { Curability of first } \\
\text { surgery in rectal cancer }\end{array}$ & $n=1,157$ & $n=57$ & 0.885 \\
\hline Complete & 1,101 & 54 & \\
\hline Incomplete & 56 & 3 & \\
\hline $\begin{array}{l}\text { Lateral node } \\
\text { dissection in rectal cancer }\end{array}$ & $n=1157$ & $n=57$ & 0.104 \\
\hline Yes & 189 & 14 & \\
\hline No & 968 & 43 & \\
\hline $\begin{array}{l}\text { Adjuvant } \\
\text { chemotherapy }\end{array}$ & $n=773$ & $n=54$ & 0.192 \\
\hline Yes & 357 & 20 & \\
\hline No & 416 & 34 & \\
\hline $\begin{array}{l}\text { Chemotherapy for } \\
\text { advanced/recurrent cases }\end{array}$ & $n=639$ & $n=55$ & 0.597 \\
\hline Yes & 220 & 17 & \\
\hline No & 419 & 38 & \\
\hline \multicolumn{4}{|l|}{ Additional resection } \\
\hline $\begin{array}{l}\text { Liver resection } \\
\text { for metastatic cases }\end{array}$ & $n=249$ & $n=11$ & 0.884 \\
\hline Yes & 73 & 3 & \\
\hline No & 176 & 8 & \\
\hline $\begin{array}{l}\text { Lung resection } \\
\text { for metastatic cases }\end{array}$ & $n=123$ & $n=5$ & 0.179 \\
\hline Yes & 33 & 0 & \\
\hline No & 90 & 5 & \\
\hline
\end{tabular}

NMA, non-mucinous adenocarcinoma; $M A$, mucinous adenocarcinoma.

However, in stage III (MA: $47.3 \%$ vs. NMA: $70.5 \%, P$ $<0.001$ ) (Figure 3) and stage IV (MA: $5.4 \%$ vs. NMA: $23.8 \%, P<0.001$ ) (Figure 4), the MA patients had a significantly worse survival rate than the NMA patients.

The recurrence pattern in stage III was analyzed (Table 5). The number of patients with any recurrence in the MA and NMA groups was 17 (31.4\%) and 182 (23.5\%), respectively. The rate of liver metastasis, distant lymph node metastasis, lung metastasis, and other site recurrence was similar between the two groups. Peritoneal dissemination $(7.4 \%$ vs. $2.3 \%, P=0.049)$, and local recurrence $(9.2 \%$ vs. $2.3 \%, P=0.013)$ were more frequently observed in the MA group. All of the locally recurrent cases in the MA group were rectal cases.

The treatment factors were compared in stage IV disease (Table 6). However, the curability of the first resection, first regimen of chemotherapy, and the rate of additional resection did not differ significantly between the MA and NMA groups. 
Table 3 Univariate analysis of overall survival in colorectal adenocarcinoma

\begin{tabular}{llcr}
\hline Variables & & HR $(\mathbf{9 5 \%} \mathbf{~ C l})$ & $\boldsymbol{P}$-value \\
\hline Gender & & 0.004 \\
& Female & 1.0 & \\
& Male & $1.349(1.098,1.656)$ &
\end{tabular}

Age, years

$$
\begin{array}{cc}
<65 & 1.0 \\
\geqq 65 & 1.217(1.001,1.480)
\end{array}
$$

Location

$\begin{array}{lc}\text { Colon } & 1.0 \\ \text { Rectum } & 1.212(1.000,1.468)\end{array}$

Size, $\mathrm{cm}$

$\begin{array}{lc}<5 & 1.0 \\ \geqq 5 m & 2.432(2.001,2.955)\end{array}$

Preoperative serum CEA, ng/ml

$$
\begin{array}{cc}
<5.0 & 1.0 \\
\geqq 5.0 & 3.223(2.654,3.915)
\end{array}
$$

Depth

of invasion ${ }^{\mathrm{a}}$
$\mathrm{T} 1, \mathrm{~T} 2$
1.0
$\mathrm{T} 3, \mathrm{~T} 4$
$6.122(4.311,8.694)$

Lymph node metastasis $^{a}$

$\begin{array}{lc}\text { No } & 1.0 \\ \text { N1, N2 } & 4.527(3.972,5.122)\end{array}$

Distant

metastasis $^{a}$

$\begin{array}{cc}\text { M0 } & 1.0 \\ \text { M1 } & 8.133(6.697,9.877)\end{array}$

Operating

facility

$\begin{array}{cc}\text { Center A } & 1.0 \\ \text { Center B } & 2.365(1.943,2.878)\end{array}$

Histological type

$$
\begin{array}{lc}
\text { NMA } & 1.0 \\
\text { MA } & 2.614(1.905,3.585)
\end{array}
$$

${ }^{\mathrm{a}}$ Staging of tumor $(\mathrm{T})$, nodes $(\mathrm{N})$, and metastases (M) [24]; $\mathrm{HR}$, hazard ratio; $\mathrm{Cl}$, confidence interval; $N M A$, non-mucinous adenocarcinoma; $M A$, mucinous adenocarcinoma.

\section{Discussion}

In this study, the data from 2,817 colorectal cancer patients who underwent surgery in two major medical centers in Yokohama city, Japan, were analyzed. In these 2,817 patients, the incidence of MA was $5.1 \%$, which generally corresponds to the rate in other Asian countries, as reported by Chew (6.0\% from Singapore) [3] and Safaee (8.5\% from Iran) [6]. Other studies from Western countries described that the proportion of MA ranged from 11
Table 4 Multivariate Cox proportional hazards analysis of overall survival in colorectal adenocarcinoma

\begin{tabular}{lccc}
\hline Variables & HR $(\mathbf{9 5 \%} \mathrm{Cl})$ & $P$-value \\
\hline Gender & Female & 1.0 & 0.020
\end{tabular}

Male $\quad 1.278(1.040,1.572)$

Age, years

$<65 \quad 1.0$

$\geqq 65 \quad 1.317(1.078,1.608)$

Location

Colon $\quad 1.0$

Rectum $\quad 1.267(1.038,1.547)$

Size, $\mathrm{cm}$

$<5 \quad 1.0$

$\geqq 5 \quad 1.184(0.961,1.459)$

Preoperative

serum CEA, ng/ml

$<5.0$

1.0

$\geqq 5.0$

$1.483(1.203,1.828)$

Depth of invasion ${ }^{\mathrm{a}}$
$\mathrm{T} 1, \mathrm{~T} 2$
1.0
T3, T4
$2.253(1.534,3.308)$

Lymph node

metastasis $^{\mathrm{a}}$

$\begin{array}{lc}\text { No } & 1.0 \\ \text { N1, N2 } & 2.427(1.893,3.105)\end{array}$

NO

$$
\text { N1, N2 }
$$$$
2.427(1.893,3.105)
$$

Distant

metastasis $^{a}$

M0

Operating

M1

$$
4.165(3.350,5.179)
$$

Center A

1.0

Center B $\quad 1.192(1.002,1.395)$

Histological

type

NMA

1.0

MA

$2.226(1.618,3.062)$

${ }^{a}$ Staging of tumor $(\mathrm{T})$, nodes $(\mathrm{N})$, and metastases (M) [24]; $\mathrm{HR}$, hazard ratio; $\mathrm{Cl}$, confidence interval; $N M A$, non-mucinous adenocarcinoma; $M A$, mucinous adenocarcinoma.

to $20 \%[4,5,7,8]$, which is higher than the rate for Asian countries. This disparity may reflect the differences in geographic, ethnic and dietary factors.

In the analysis of the patients' characteristics, the MA group had worse clinical factors, including larger primary lesions, deeper invasion, higher rates of nodal and distant metastasis, and a larger number of metastatic sites compared to the NMA group. The previous reports showed that younger patients, larger tumors, higher 


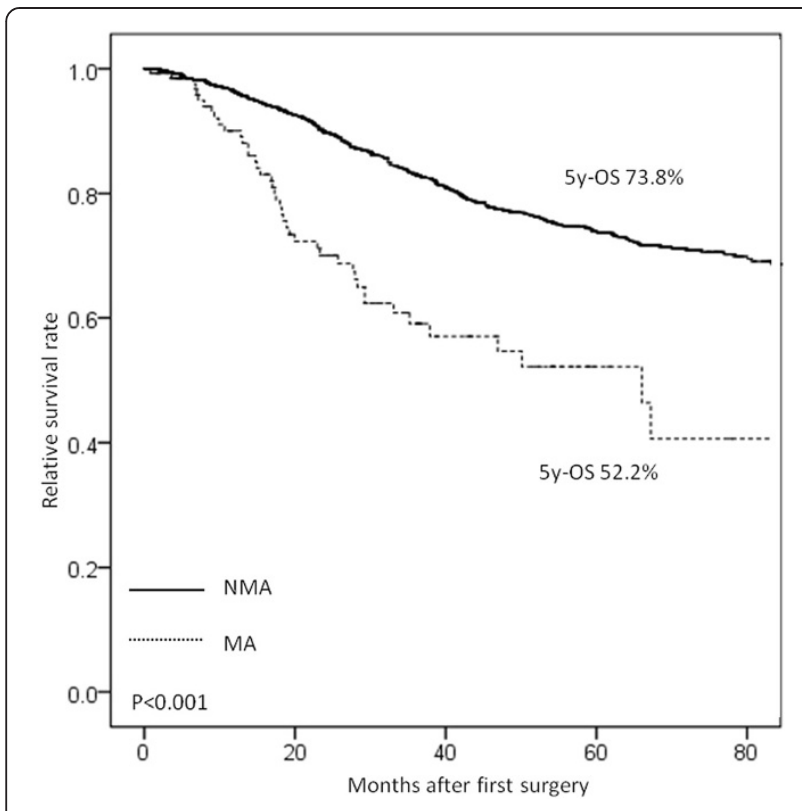

Figure 1 The 5-year relative survival rate of patients with mucinous adenocarcinoma (52.2\%) was significantly worse than those with non-mucinous adenocarcinoma $(73.8 \%)$ as determined by the log-rank test $(\boldsymbol{P}<\mathbf{0 . 0 0 1}) .5$ YOS, 5 -year overall survival.

rates of lymph node metastasis, and peritoneal metastasis were correlated with MA histology when compared to NMA histology [17-19], which was mostly in agreement with our results.

The reason why MA patients have worse characteristics than NMA patients is not fully understood. Sugarbaker $e t$

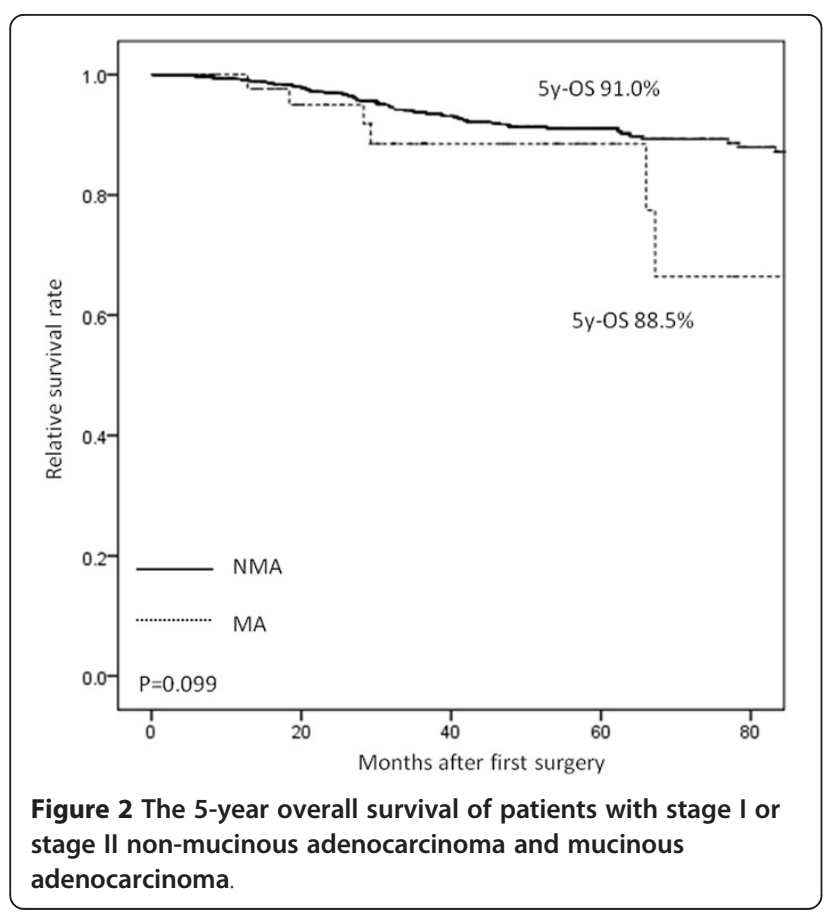

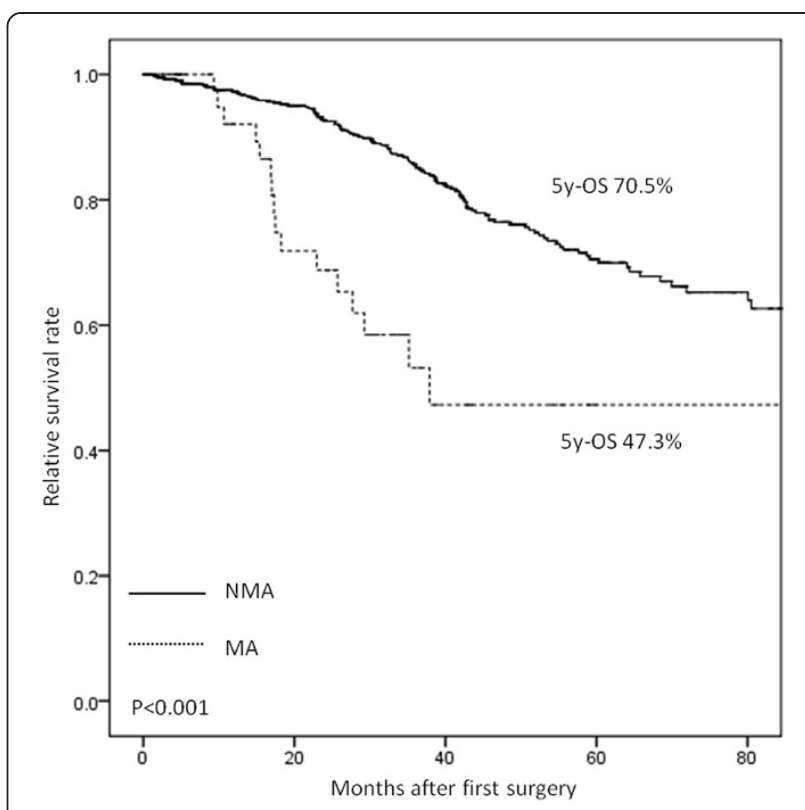

Figure 3 The 5 -year overall survival of patients with stage III non-mucinous adenocarcinoma and mucinous adenocarcinoma.

al. demonstrated that the more malignant characteristics of MA may be partly due to the production of mucus under pressure, which allows the MA cells to gain access to the peritoneal cavity. Moreover, the fluid produced by MA is taken up by the lymphatic system, which might help to promote tumor spread into regional lymph nodes [25].

It remains unclear whether MA adversely affects survival in colorectal cancer patients. In some studies, MA

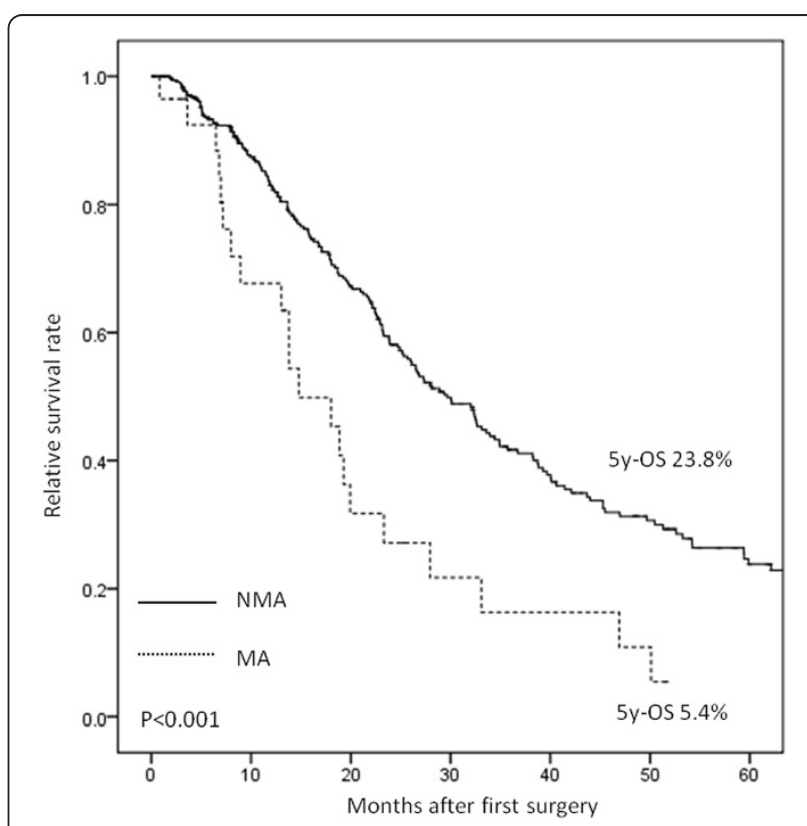

Figure 4 The 5 -year overall survival of patients with stage IV non-mucinous adenocarcinoma and mucinous adenocarcinoma 
Table 5 The comparison of recurrent pattern in patients with stage III disease

\begin{tabular}{|c|c|c|c|}
\hline Recurrent pattern & NMA & MA & $P$-value \\
\hline & $\overline{(n=774)}$ & $\overline{(n=54)}$ & \\
\hline Liver metastasis & $80(10.3 \%)$ & $4(7.4 \%)$ & 0.643 \\
\hline Peritoneal metastasis & $18(2.3 \%)$ & $4(7.4 \%)$ & 0.049 \\
\hline Distant lymph node metastasis & $30(3.8 \%)$ & $1(1.8 \%)$ & 0.715 \\
\hline Lung metastasis & $60(7.7 \%)$ & $4(7.4 \%)$ & 1.000 \\
\hline Local recurrence & $18(2.3 \%)$ & $5(9.2 \%)$ & 0.013 \\
\hline Other site recurrence & $16(2.0 \%)$ & $3(5.5 \%)$ & 0.121 \\
\hline
\end{tabular}

NMA, non-mucinous adenocarcinoma; $M A$, mucinous adenocarcinoma.

has been shown to be a significant prognostic factor [5,17,20-23], while others have found no such evidence $[13,14,26]$. Both the American Joint Committee on Cancer and the College of American Pathologists consider that the MA subtype has not been proven to be a statistically significant prognostic factor [14,27]. The contradictions in the various studies may be explained by the geographical and racial variations in the epidemiology of colorectal cancer [28,29], disparities in the criteria for defining MA [22,30], and insufficient sample sizes to disclose any differences. In this study, we compared the relative survival rate of MA and NMA patients in a relatively large number of patients, and revealed that the MA patients had significantly worse survival than the NMA patients. Furthermore, multivariate analysis demonstrated that MA histology is an independent prognostic factor.

Based on our findings, we also performed an investigation to establish an optimal therapeutic strategy for MA. To exclude the bias caused by stage, which is related to the status of lymph node metastasis and distant metastasis,

Table 6 Comparison of treatment factors in patients with stage IV disease

\begin{tabular}{|c|c|c|c|}
\hline Treatment factors & NMA & MA & P-value \\
\hline & $(n=349)$ & $(n=28)$ & \\
\hline Curability of first surgery & & & 0.353 \\
\hline Complete & $96(27.5 \%)$ & $10(35.7 \%)$ & \\
\hline Incomplete & $253(72.5 \%)$ & $18(64.3 \%)$ & \\
\hline Regimen of first chemotherapy & & & 0.362 \\
\hline OXA-based & $25(7.1 \%)$ & $3(10.7 \%)$ & \\
\hline |RI-based & $18(5.1 \%)$ & $3(10.7 \%)$ & \\
\hline 5-FU intravenously & $43(12.3 \%)$ & $4(14.2 \%)$ & \\
\hline 5-FU orally & $36(10.3 \%)$ & $4(14.2 \%)$ & \\
\hline \multicolumn{4}{|l|}{ Additional resection } \\
\hline Liver resection & 75 (21.4\%) & $3(10.7 \%)$ & 0.228 \\
\hline Lung resection & $10(2.8 \%)$ & $0(0.0 \%)$ & 1.000 \\
\hline
\end{tabular}

$O X A$, oxaliplatin; IRI, irinotecan; 5-FU, 5-fluolouracil; $N M A$, non-mucinous adenocarcinoma; $M A$, mucinous adenocarcinoma. we divided all cases into three subgroups and analyzed the relative survival rate in each group. Consequently, the prognosis of patients with MA was similar to that of patients with NMA in stage I/II, whereas it was significantly worse for MA patients in both stage III and stage IV. Some of the above-mentioned literature supports the relatively worse survival of MA patients when the subjects are limited to stage III and stage IV disease [8,18,21], which is consistent with our results. According to these results, we speculated that the worse survival of stage III and IV may contribute to the relatively poor overall prognosis of the MA cases.

In the analysis of the recurrence pattern of stage III disease, the incidence of local recurrence and peritoneal metastasis was significantly higher in patients with MA than in those with NMA. In addition, all cases of local recurrence in the MA group were in patients with rectal disease. Differences in the rates of liver, lung, and distant lymph node metastases were not statistically significant.

In stage IV disease, we compared the treatment factors, including the curability of the first resection, first chemotherapeutic regimen, and the need for additional resection (liver and lung resection). This analysis revealed that equivalent treatments were performed for both MA and NMA patients.

Our results indicate that better management of the local and peritoneal recurrence of stage III disease may improve the survival of MA patients. In terms of local control, previous studies have shown that the difference in survival between MA and NMA patients was mainly related to tumors with a rectal location [18], because MA cases are more likely to be locally recurrent [31], which supports our present results. Green et al. pointed out that the lymphatic drainage of the pelvis is more extensive and varied compared with that of the colon [5].

In the NCCN guidelines for treatment of rectal cancer [16], it is recommended to perform pre- or postoperative radiation therapy for patients with $\mathrm{T} 3$ to $\mathrm{T} 4$, or $\mathrm{N} 1$ to N2 disease. However, In Japan, Sugihara et al. showed that the five-year overall survival and the five-year locally controlling ratio in patients with $\mathrm{T} 3$ to $\mathrm{T} 4$ rectal cancer treated by TME plus lateral node dissection, was $79.7 \%$ and $92.0 \%$ respectively [32]. Consequently, TME and lateral node dissection is considered a standard therapy for T3 to T4 rectal cancer, and neo- or adjuvant radiation therapy is not commonly selected in Japan.

Considering our result, the application of pre- or postoperative radiation therapy [33-36] may be a strategy to prevent the development of local recurrence in MA cases.

We also found that peritoneal metastasis was a significant site of recurrence for MA in stage III disease. Metastasis to the peritoneum is regarded to be a fatal manifestation of gastrointestinal cancer, and is associated with a median 
survival time of 5.2 to 12.6 months [37,38]. In terms of the sensitivity to chemotherapy, previous reports have demonstrated that a mucinous histology generally predicts a reduced response to a 5-FU-, oxaliplatin-, and irinotecanbased regimen $[39,40]$.

It is well known that there are several molecular pathways involving oncogene (for example KRAS) and the suppressor gene in colorectal carcinogenesis [41], and cetuximab is an established drug used for downstream blocking of the EGFR-KRAS pathway. However, according to Hanski et al., MA histology is characterized by a high frequency of KRAS mutations, and a high frequency of microsatellite instability [9], suggesting that MA histology generally has drug-resistant properties of cetuximab. It is also revealed that MA has different molecular alterations and genetic subtypes to NMA [42]. Detailed molecular and genetic analyses to detect specific pathways of MA will help to develop new systemic chemotherapy, which is necessary to improve peritoneal metastasis and overall survival in patients with MA.

\section{Conclusion}

Our study indentified MA histology as an independent prognostic factor, and revealed that MA was associated with worse survival compared with NMA in patients with stage III and IV disease. The ability of MA to disseminate and infiltrate more aggressively than NMA appears to be responsible, at least in part, for the higher rate of failure in stage III and IV, which are the main reasons for the overall poorer prognosis of patients with MA. Controlling local recurrence and managing peritoneal metastasis are necessary to improve the overall survival in patients with MA.

Besides considering radiation therapy after TME and radical lymph node dissection for locally advanced rectal cases, further investigations focusing on the genetic and molecular characteristics of MA, will help better management of MA histology.

\section{Abbreviations}

CEA: Carcinoembryonic antigen; 5-FU: 5-fluolouracil; IRI: Irinotecan; MA: Mucinous adenocarcinoma; NCCN: National Comprehensive Cancer Network NMA, non-mucinous adenocarcinoma; OXA: Oxaliplatin; TME: Total mesorectal excision; TNM: Tumor, node, metastases.

\section{Competing interests}

There are no financial or non-financial competing interests to declare in relation to this manuscript.

\section{Author details}

${ }^{1}$ Department of Gastroenterological Surgery, Kanagawa Cancer Center, 1-1-2 Nakao, Asahi-ku, Yokohama, Kanagawa 241-0815, Japan. ${ }^{2}$ Gastroenterological Center, Yokohama City University Medical Center, 4-57 Urafune-cho, Minami-ku, Yokohama, Kanagawa 232-0024, Japan. ${ }^{3}$ Department of Surgery, Yokohama City University, 3-9 Fukuura, Kanazawa-ku, Yokohama, Kanagawa 236-0004, Japan.

\section{Authors' contributions}

MN carried out the analysis of data and wrote the manuscript. MS, TW, HT, NY, SM, KW, TG, TO, SF, CK, NY, YR, MM, and MA made the database of patients. All authors read and approved the final manuscript.

Received: 16 January 2012 Accepted: 15 June 2012

Published: 15 June 2012

\section{References}

1. Weitz J, Koch M, Debus J, Hohler T, Galle PR, Buchler MW: Colorectal cancer. Lancet 2005, 365:153-165.

2. Hamilton SR, Aaltonen LA: Pathology and Genetics, Tumours of the Digestive System. In World Health Organization Classification of Tumours. 3rd edition. Lyon: IARC; 2000.

3. Chew MH, Yeo SA, Ng ZP, Lim KH, Koh PK, Ng KH, Eu KW: Critical analysis of mucin and signet ring cell as prognostic factors in an Asian population of 2,764 sporadic colorectal cancers. Int I Colorectal Dis 2010, 25:1221-1229

4. Thomas RM, Sobin LH: Gastrointestinal cancer. Cancer 1995, 75:154-170.

5. Green JB, Timmcke AE, Mitchell WT, Hicks TC, Gathright JB Jr, Ray JE: Mucinous carcinoma-just another colon cancer? Dis Colon Rectum 1993, 36:49-54.

6. Safaee A, Moghimi-Dehkordi B, Fatemi SR, Ghiasi S, Nemati-Malek F, Zali MR: Characteristics of colorectal mucinous adenocarcinoma in Iran. Asian Pac $J$ Cancer Prev 2010, 11:1373-1375.

7. Symonds DA, Vickery AL: Mucinous carcinoma of the colon and rectum. Cancer 1976, 37:1891-1900.

8. Xie L, Villeneuve PJ, Shaw A: Survival of patients diagnosed with either colorectal mucinous or non-mucinous adenocarcinoma: a populationbased study in Canada. Int J Oncol 2009, 34:1109-1115.

9. Hanski C: Is mucinous carcinoma of the colorectum a distinct genetic entity? Br J Cancer 1995, 72:1350-1356.

10. Zhang H, Evertsson S, Sun X: Clinicopathological and genetic characteristics of mucinous carcinomas in the colorectum. Int J Oncol 1999, 14:1057-1061.

11. Kim DH, Kim JW, Cho JH, Baek SH, Kakar S, Kim GE, Sleisenger MH, Kim YS: Expression of mucin core proteins, trefoil factors, APC and p21 in subsets of colorectal polyps and cancers suggests a distinct pathway of pathogenesis of mucinous carcinoma of the colorectum. Int J Oncol 2005, 27:957-964

12. Song GA, Deng G, Bell I, Kakar S, Sleisenger MH, Kim YS: Mucinous carcinomas of the colorectum have distinct molecular genetic characteristics. Int J Oncol 2005, 26:745-750.

13. Purdie CA, Piris J: Histopathological grade, mucinous differentiation and DNA ploidy in relation to prognosis in colorectal carcinoma. Histopathology 2000, 36:121-126.

14. Compton C, Fenoglio-Preiser CM, Pettigrew N, Fielding LP: American Joint Committee on Cancer Prognostic Factors Consensus Conference: Colorectal Working Group. Cancer 2000, 88:1739-1757.

15. Engstrom PF, Arnoletti JP, Benson AB 3rd, Chen YJ, Choti MA, Cooper HS, Covey A, Dilawari RA, Early DS, Enzinger PC, Fakih MG, Fleshman J Jr, Fuchs C, Grem JL, Kiel K, Knol JA, Leong LA, Lin E, Mulcahy MF, Rao S, Ryan DP, Saltz L, Shibata D, Skibber JM, Sofocleous C, Thomas J, Venook AP, Willett C: National Comprehensive Cancer Network: NCCN Clinical Practice Guidelines in Oncology: colon cancer. J Natl Compr Canc Netw 2009, 7:778-831.

16. Engstrom PF, Arnoletti JP, Benson AB 3rd, Chen YJ, Choti MA, Cooper HS, Covey A, Dilawari RA, Early DS, Enzinger PC, Fakih MG, Fleshman J Jr, Fuchs C, Grem JL, Kiel K, Knol JA, Leong LA, Lin E, Mulcahy MF, Rao S, Ryan DP, Saltz L, Shibata D, Skibber JM, Sofocleous C, Thomas J, Venook AP, Willett C: National Comprehensive Cancer Network: NCCN Clinical Practice Guidelines in Oncology: rectal cancer. J Natl Compr Canc Netw 2009, 7:838-881.

17. Nozoe T, Anai H, Nasu S, Sugimachi K: Clinicopathological characteristics of mucinous carcinoma of the colon and rectum. J Surg Oncol 2000, 75:103-107.

18. Du W, Mah JT, Lee J, Sankila R, Sankaranarayanan R, Chia KS: Incidence and survival of mucinous adenocarcinoma of the colorectum: a populationbased study from an Asian country. Dis Colon Rectum 2004, 47:78-85.

19. Maksimovic S: Survival rates of patients with mucinous adenocarcinoma of the colorectum. Med Arh 2007, 61:26-29. 
20. Secco GB, Fardelli R, Campora E, Lapertosa G, Gentile R, Zoli S, Prior C: Primary mucinous adenocarcinomas and signet-ring cell carcinomas of colon and rectum. Oncology 1994, 51:30-34.

21. Consorti F, Lorenzotti A, Midiri G, Di Paola M: Prognostic significance of mucinous carcinoma of colon and rectum: a prospective case-control study. J Surg Oncol 2000, 73:70-74.

22. Kanemitsu Y, Kato T, Hirai T, Yasui K, Morimoto T, Shimizu Y, Kodera Y, Yamamura Y: Survival after curative resection for mucinous adenocarcinoma of the colorectum. Dis Colon Rectum 2003, 46:160-167.

23. Papadopoulos VN, Michalopoulos A, Netta S, Basdanis G, Paramythiotis D, Zatagias A, Berovalis P, Harlaftis N: Prognostic significance of mucinous component in colorectal carcinoma. Tech Coloproctol 2004, 8(Suppl 1):123-125.

24. Edge SB, Byrd DR, Compton CC, Fritz A: AJCC Cancer Staging Manual 7th edn. New York: AJCC; 2010

25. Sugarbaker PH: Mucinous colorectal carcinoma. J Surg Oncol 2001, 77:282283.

26. Galandiuk S, Wieand HS, Moertel CG, Cha SS, Fitzgibbons RJ Jr, Pemberton $\mathrm{JH}$, Wolff BG: Patterns of recurrence after curative resection of carcinoma of the colon and rectum. Surg Gynecol Obstet 1992, 174:27-32.

27. Compton CC, Fielding LP, Burgart LJ, Conley B, Cooper HS, Hamilton SR, Hammond ME, Henson DE, Hutter RV, Nagle R, Nielsen ML, Sargent DJ, Taylor CR, Welton M, Willett C: Prognostic factors in colorectal cancer. College of American Pathologists Consensus Statement 1999. Arch Pathol Lab Med 2000, 124:979-994.

28. Winder T, Lenz HJ: Mucinous adenocarcinomas with intra-abdominal dissemination: a review of current therapy. Oncologist 2010, 15:836-844.

29. Levin KE, Dozois RR: Epidemiology of large bowel cancer. World J Surg 1991, 15:562-567.

30. Wu CS, Tung SY, Chen PC, Kuo YC: Clinicopathological study of colorectal mucinous carcinoma in Taiwan: a multivariate analysis. J Gastroenterol Hepatol 1996, 11:77-81.

31. Umpleby HC, Ranson DL, Williamson RC: Peculiarities of mucinous colorectal carcinoma. Br J Surg 1985, 72:715-718.

32. Sugihara K, Kobayashi H, Kato T, Mori T, Mochizuki H, Kameoka S, Shirouzu K, Muto T: Indication and benefit of pelvic sidewall dissection for rectal cancer. Dis Colon Rectum 2006, 49:1663-1672.

33. Wong RK, Berry S, Spithoff K, Simunovic M, Chan K, Agboola O, Dingle B: Preoperative or postoperative therapy for stage II or III rectal cancer: an updated practice guideline. Clin Oncol (R Coll Radiol) 2010, 22:265-271.

34. Min BS, Kim NK, Ko YT, Lee KY, Baek SH, Cho CH, Sohn SK: Long-term oncologic results of patients with distal rectal cancer treated by local excision with or without adjuvant treatment. Int J Colorectal Dis 2007, 22:1325-1330.

35. Kurt M, Ozkan L, Yilmazlar T, Ercan I, Zorluoglu A, Memik F, Engin K: Postoperative concomitant chemoradiotherapy in locally advanced rectal cancer. Hepatogastroenterology 2005, 52:1411-1415.

36. Minsky BD: Adjuvant therapy for rectal cancer-the transatlantic view. Colorectal Dis 2003, 5:416-422.

37. Sadeghi B, Arvieux C, Glehen O, Beaujard AC, Rivoire M, Baulieux J, Fontaumard E, Brachet A, Caillot $J$, Faure $J$, Poercheron J, Peix $J$, François $Y$, Vignal J, Gilly FN: Peritoneal carcinomatosis from non-gynecologic malignancies: results of the EVOCAPE 1 multicentric prospective study. Cancer 2000, 88:358-363.

38. Verwaal VJ, van Ruth $\mathrm{S}$, de Bree E, van Sloothen GW, van Tinteren $H$, Boot $H_{\text {, }}$ Zoetmulder FA: Randomized trial of cytoreduction and hyperthermic intraperitoneal chemotherapy versus systemic chemotherapy and palliative surgery in patients with peritoneal carcinomatosis of colorectal cancer. J Clin Oncol 2003, 21:3737-3743.

39. Negri FV, Wotherspoon A, Cunningham D, Norman AR, Chong G, Ross PJ: Mucinous histology predicts for reduced fluorouracil responsiveness and survival in advanced colorectal cancer. Ann Oncol 2005, 16:1305-1310.

40. Catalano V, Loupakis F, Graziano F, Torresi U, Bisonni R, Mari D, Fornaro L, Baldelli AM, Giordani P, Rossi D, Alessandroni P, Giustini L, Silva RR, Falcone A, D'Emidio S, Fedeli SL: Mucinous histology predicts for poor response rate and overall survival of patients with colorectal cancer and treated with first-line oxaliplatin- and/or irinotecan-based chemotherapy. $\mathrm{Br} J$ Cancer 2009, 100:881-887.

41. Vogelstein B, Fearon ER, Hamilton SR, Kern SE, Preisinger AC, Leppert M, Nakamura Y, White R, Smits AM, Bos JL: Genetic alterations during colorectal-tumor development. N Engl J Med 1988, 319:525-532.
42. Leopoldo S, Lorena B, Cinzia A, Gabriella DC, Angela Luciana B, Renato C, Antonio M, Carlo S, Cristina P, Stefano C, Maurizio T, Luigi R, Cesare B: Two subtypes of mucinous adenocarcinoma of the colorectum: clinicopathological and genetic features. Ann Surg Oncol 2008, 15:14291439

\section{doi:10.1186/1477-7819-10-109}

Cite this article as: Numata et al.: The clinicopathological features of colorectal mucinous adenocarcinoma and a therapeutic strategy for the disease. World Journal of Surgical Oncology 2012 10:109.

\section{Submit your next manuscript to BioMed Central and take full advantage of:}

- Convenient online submission

- Thorough peer review

- No space constraints or color figure charges

- Immediate publication on acceptance

- Inclusion in PubMed, CAS, Scopus and Google Scholar

- Research which is freely available for redistribution 